\title{
Significance of Lewis Phenotyping Using Saliva and Gastric Tissue: Comparison with the Lewis Phenotype Inferred from Lewis and Secretor Genotypes
}

\author{
Yun Ji Hong, 1,2 Sang Mee Hwang, 1,2 Taek Soo Kim,, ${ }^{1,2}$ Eun Young Song, ${ }^{1}$ \\ Kyoung Un Park, ${ }^{1,2}$ Junghan Song, ${ }^{1,2}$ and Kyou-Sup Han ${ }^{1}$ \\ ${ }^{1}$ Department of Laboratory Medicine, Seoul National University College of Medicine, Seoul 110-744, Republic of Korea \\ ${ }^{2}$ Department of Laboratory Medicine, Seoul National University Bundang Hospital, 173-82 Gumiro, Bundanggu, \\ Seongnam, Gyeonggido 463-707, Republic of Korea \\ Correspondence should be addressed to Kyoung Un Park; m91w95pf@snu.ac.kr
}

Received 31 December 2013; Revised 9 February 2014; Accepted 3 March 2014; Published 24 March 2014

Academic Editor: Giulio Mengozzi

Copyright (c) 2014 Yun Ji Hong et al. This is an open access article distributed under the Creative Commons Attribution License, which permits unrestricted use, distribution, and reproduction in any medium, provided the original work is properly cited.

Lewis phenotypes using various types of specimen were compared with the Lewis phenotype predicted from Lewis and Secretor genotypes. This is the first logical step in explaining the association between the Lewis expression and Helicobacter pylori. We performed a study of the followings on 209 patients who underwent routine gastroscopy: erythrocyte and saliva Lewis phenotyping, gastric Lewis phenotyping by the tissue array, and the Lewis and Secretor genes genotyping. The results of phenotyping were as follows [Le $(\mathrm{a}-\mathrm{b}-), \mathrm{Le}(\mathrm{a}+\mathrm{b}-), \mathrm{Le}(\mathrm{a}-\mathrm{b}+)$, and $\mathrm{Le}(\mathrm{a}+\mathrm{b}+)$, respectively, in order]: erythrocyte $(12.4 \%, 25.8 \%, 61.2 \%$, and $0.5 \%)$; saliva $(2.4 \%, 27.3 \%, 70.3 \%$, and $0.0 \%)$; gastric mucosa $(8.1 \%, 6.7 \%, 45.5 \%$, and $39.7 \%)$. The frequency of $L e, l e^{59 / 508}, l e^{59 / 1067}$, and $l e^{59}$ alleles was $74.6 \%, 21.3 \%, 3.1 \%$, and $1.0 \%$, respectively, among 418 alleles. The saliva Lewis phenotype was completely consistent with the Lewis phenotype inferred from Lewis and Secretor genotypes, but that of gastric mucosa could not be predicted from genotypes. Lewis phenotyping using erythrocytes is only adequate for transfusion needs. Saliva testing for the Lewis phenotype is a more reliable method for determining the peripheral Lewis phenotype of an individual and the gastric Lewis phenotype must be used for the study on the association between Helicobacter pylori and the Lewis phenotype.

\section{Introduction}

The Lewis histoblood group system consists of two major antigens, $\mathrm{Le}^{\mathrm{a}}$ and $\mathrm{Le}^{\mathrm{b}}$, and three common phenotypes, $\mathrm{Le}(\mathrm{a}-\mathrm{b}-), \mathrm{Le}(\mathrm{a}+\mathrm{b}-)$, and $\mathrm{Le}(\mathrm{a}-\mathrm{b}+)$. The Lewis determinants are oligosaccharides which are synthesized by the sequential addition of sugar units to oligosaccharide chains by fucosyltransferases encoded by $H$, Secretor, and Lewis genes. The type 2 oligosaccharide chains are expressed mainly on erythrocytes and on vascular endothelial cells, while the type 1 oligosaccharide chains are expressed on the digestive and respiratory tracts and in secretions. The classical Lewis determinants $\left(\mathrm{Le}^{\mathrm{a}}\right.$ and $\mathrm{Le}^{\mathrm{b}}$ ) are composed of type 1 chains [1]. The $\mathrm{Le}^{\mathrm{a}}$ antigen is synthesized from a type 1 precursor substrate by Lewis-encoded $\alpha(1,3 / 1,4)$ fucosyltransferase, while the Le ${ }^{\mathrm{b}}$ antigen is synthesized from a type $1 \mathrm{H}$ substrate by the enzyme.

The eleven fucosyltransferase (FUT) genes encoding human fucosyltransferases have been isolated [2]. The FUT1 $(H)$ and FUT2 (Secretor) encode $\alpha(1,2)$ fucosyltransferases, and the FUT3-FUT9 encode $\alpha(1,3 / 1,4$ or 1,3$)$ fucosyltransferases. FUT1, FUT2, FUT3, and FUT6 are polymorphic [1]. Alpha(1,2)fucosyltransferase adds a fucose molecule to the terminal galactose of a precursor to form the $\mathrm{H}$ antigen. There are two distinct $\alpha(1,2)$ fucosyltransferases in sera and tissues. One is the $\mathrm{H}$-encoded fucosyltransferase (H enzyme) and the other is the Secretor-encoded fucosyltransferase (secretor enzyme). The $\mathrm{H}$ enzyme regulates the expression of 
the $\mathrm{H}$ antigen mainly on erythrocyte membranes and in vascular endothelial cells, while the secretor enzyme regulates the expression of the $\mathrm{H}$ antigen mainly on the gastrointestinal epithelial cells and in body fluids such as saliva.

The Lewis antigens are not intrinsic to the erythrocytes but adsorbed onto erythrocyte membranes from plasma. Accordingly, the Lewis phenotyping from erythrocytes is difficult and is sometimes misjudged because of weak hemagglutination due to low titers and low specificities of the reagents. There are two alleles at the Lewis locus, the Le which encodes a functional fucosyltransferase and the le which encodes a nonfunctional enzyme. An individual homozygous for le expresses neither $\mathrm{Le}^{\mathrm{a}}$ nor $\mathrm{Le}^{\mathrm{b}}$ antigen and has the Le $(\mathrm{a}-\mathrm{b}-)$ erythrocyte phenotype. Several polymorphisms have been described in the Lewis and Secretor genes [310]. It is conceivable that Lewis antigen expression in digestive organs is biologically much more important than the expression in erythrocytes. The studies on Helicobacter pylori suggested that the adherence of $H$. pylori to the human gastric epithelial lining can be mediated by the blood-group antigenbinding adhesion (BabA) that targets human fucosylated blood group antigens type $1 \mathrm{H}$ and $\mathrm{Le}^{\mathrm{b}}$ [11-13]. The presence of the $b a b A 2$ gene, encoding for $\mathrm{BabA}$, in the $H$. pylori genome is crucial for $H$. pylori-related pathogenesis [13].

In this study, various Lewis phenotypes using saliva, erythrocytes, and gastric mucosa were compared with the Lewis phenotype predicted from Lewis and Secretor genotypes to establish the significance of Lewis phenotyping using saliva and gastric tissue. This is the first logical step in explaining the association between the Lewis expression and Helicobacter pylori.

\section{Materials and Methods}

2.1. Blood Sample Processing. The subjects were 209 adult patients who underwent routine gastroscopy at a health promotion center because of upper gastrointestinal symptoms. Specimens were collected after the patients had given informed consent. The procedures in this study were in accordance with the National Institutes of Health Bioethics Resources for research on human specimens and the World Medical Association Declaration of Helsinki (Ethical Principles for Medical Research Involving Human Subjects). Peripheral blood was collected in one EDTA tube and one plain tube. The blood of EDTA tube was separated into buffy coat and plasma on the day of blood sampling. The buffy coat was stored at $-70^{\circ} \mathrm{C}$. DNA for the determination of the Lewis and Secretor genotypes was extracted from the buffy coat using the Puregene DNA Kit (Gentra, Minneapolis, MN, USA) according to the manufacturer's instructions.

2.2. Saliva Sample Processing. Saliva samples were donated for detection of Lewis antigens before undergoing endoscopy. Saliva ( 5 to $10 \mathrm{~mL}$ ) was collected in a wide-mouthed test tube. The saliva was centrifuged at $1000 \times \mathrm{g}$ for 10 minutes. The supernatant was transferred to a clean test tube and placed in boiling water bath for 10 minutes to inactivate salivary enzymes. After recentrifuging at $1000 \times \mathrm{g}$ for 10 minutes, the supernatant fluid was diluted with an equal volume of saline and stored at $-70^{\circ} \mathrm{C}$.

2.3. Erythrocyte Phenotyping for the Lewis Antigens. Ortho BioClone 2.0 anti-Le ${ }^{\mathrm{a}}$ and anti-Le $\mathrm{b}^{\mathrm{b}}$ monoclonal antibodies (Ortho-Clinical Diagnostics, Inc., Raritan, NJ, USA) were used for hemagglutination tests according to the manufacturer's instructions.

2.4. Saliva Testing for the Lewis Phenotypes. The Lewis antigens in saliva were tested by hemagglutination inhibition methods with Lewis antisera. Doubling dilutions of the appropriate blood grouping reagent were prepared beforehand, for the selection of blood grouping reagent dilution. One drop of $3 \%$ saline suspension of red cells was added to one drop of each reagent dilution. $\operatorname{Le}(\mathrm{a}+\mathrm{b}-)$ and $\operatorname{Le}(\mathrm{a}-\mathrm{b}+)$ red cells were used to determine Lewis phenotypes. Each tube was centrifuged and examined macroscopically for agglutination. The highest reagent dilution that gives $2+$ agglutination was selected. For the hemagglutination inhibition test, one drop of appropriately diluted blood grouping reagent was mixed with one drop of the appropriate saliva and the mixture was incubated for 10 minutes at room temperature. One drop of $3 \%$ saline suspension of washed indicator cells was added to each tube. The tube contents were incubated for 60 minutes at room temperature. Each tube was centrifuged and inspected macroscopically for agglutination. Saline control tube was included in each test.

2.5. Tissue Array Method. Core tissue biopsies (2 $\mathrm{mm}$ in diameter) were taken from individual paraffin-embedded gastric tissues (donor blocks) and arranged in a new recipient paraffin block (tissue array block) using a trephine apparatus (Superbiochips Laboratories, Seoul, Korea). Each tissue array block contained up to sixty cases. Sections of $4 \mu \mathrm{m}$ were cut from each tissue array block, deparaffinized, and dehydrated.

2.6. Gastric Immunostaining for the Lew Phenotypes. Immunohistochemical phenotyping of the gastric tissue specimens for Lewis antigens was performed using a streptavidin peroxidase procedure after an antigen retrieval process using microwaves or autoclaves. The monoclonal antibodies used for detection of gastric Lewis antigens were the antibody to $\mathrm{Le}^{\mathrm{a}}$ and the antibody to $\mathrm{Le}^{\mathrm{b}}$ (Signet Laboratories, Inc., Dedham, MA, USA). The same pathologist evaluated all slides blindly. The results of immunostaining were considered to be positive if more than $20 \%$ of the cells showed staining.

2.7. Genotyping for the Lewis Genes. The Lewis genotype was determined for the T59G, G508A, and T1067A polymorphic sites. The $l e^{59 / 508}$ and $l e^{59 / 1067}$ alleles confer very low enzymatic activity relative to the $L e$ and $L e^{59}$ alleles [4]. The $L e^{59}$ allele confers about the same enzymatic activity as the Le allele [3].

(1) PCR-CTPP for the Detection of the T59G Mutation. The T59G mutation was determined by the polymerase chain 
reaction with confronting two-pair primers (PCR-CTPP) [14]. The oligonucleotide primers (Bioneer Corporation, Daejeon, Korea) used in the PCR-CTPP were [15] Le59-F1, $5^{\prime}$-CCA TGG ATC CCC TGG GTG-3'; Le59-R1, 5'-CCA CCA GCA GCT GAA ATA GCC-3'; Le59-F2, 5' -CGC TGT CTG GCC GCA CT-3'; Le59-R2, 5'-GAA GGT GGG AGG CGT GAC TTA-3'. PCR was performed in $25 \mu \mathrm{L}$ reaction mixture containing $10 \mathrm{pmol}$ each of the four primers, $2 \mu \mathrm{L}$ of DNA, 0.6 units of Taq polymerase (Takara, Shiga, Japan), $0.2 \mathrm{mM}$ dNTPs, $2.5 \mu \mathrm{L} \mathrm{10x}$ PCR buffer, $1.5 \mathrm{mM} \mathrm{MgCl}_{2}$, and $2.5 \mu \mathrm{L}$ of glycerol. PCR conditions were 3 minutes of initial denaturation at $94^{\circ} \mathrm{C}$, followed by 35 cycles of denaturing at $94^{\circ} \mathrm{C}$ for 30 seconds, annealing at $66^{\circ} \mathrm{C}$ for 30 seconds and extension at $72^{\circ} \mathrm{C}$ for 30 seconds, and final extension at $72^{\circ} \mathrm{C}$ for 5 minutes. PCR products underwent electrophoresis in a $3 \%$ agarose gel and were stained by ethidium bromide. In the T59G detection by the PCR-CTPP, the $329 \mathrm{bp}$ and $81 \mathrm{bp}$ bands represented the $\mathrm{T}$ allele and $\mathrm{G}$ allele, respectively. A common band of $373 \mathrm{bp}$ appeared for both alleles.

(2) PCR-RFLP for the Detection of the G508A and T1067A Mutations. The G508A and T1067A mutations were determined by the polymerase chain reaction-restriction fragment length polymorphism (PCR-RFLP). For detecting the G508A mutation, genomic DNA was combined with the 508-F $\left(5^{\prime}-\right.$ ACT TGG AGC CAC CCC CTA ACT GCC A- $\left.3^{\prime}\right)$ and 508R (5'-TGA GTC CGG CTT CCA GTT GGA CAC C- $3^{\prime}$ ) primers (10 pmol) [6] in $25 \mu \mathrm{L}$ reaction mixture containing 0.6 units of Taq polymerase (Takara, Shiga, Japan), $0.2 \mathrm{mM}$ dNTPs, $2.5 \mu \mathrm{L} 10 \mathrm{x}$ PCR buffer, and $1.5 \mathrm{mM} \mathrm{MgCl}_{2}$. Thirty cycles ( 30 seconds at $94^{\circ} \mathrm{C}, 30$ seconds at $70^{\circ} \mathrm{C}$, and 30 seconds at $72^{\circ} \mathrm{C}$ ) were run, and then the 206 bp products were digested by PvuII enzyme and subjected to separation through $3 \%$ agarose gel electrophoresis.

For the T1067A mutation, the first PCR with the primers [4] Le-F ( $5^{\prime}$-CTC CCG ACA GGA CAC CAC TCC CA-3') and Le-R ( $5^{\prime}$-CTC AAG CTT CGT GCC GTG ATG ATC TCT CTG CAC- $3^{\prime}$ ) was carried out in the same PCR buffer as in the PCR for detection of the G508A mutation. Thirty cycles $\left(30\right.$ seconds at $94^{\circ} \mathrm{C}, 30$ seconds at $70^{\circ} \mathrm{C}$, and 45 seconds at $72^{\circ} \mathrm{C}$ ) were run. For the second PCR amplification, the first PCR products were used as the template by $1067-\mathrm{F}\left(5^{\prime}-\right.$ CGC TCC TTC AGC TGG GCA CTG GA-3') and 1067-R (5' CGG CCT CTC AGG TGA ACC AAG AAG CT-3') primers [4]. Thirty cycles $\left(30\right.$ seconds at $94^{\circ} \mathrm{C}, 30$ seconds at $62^{\circ} \mathrm{C}$, and 30 seconds at $72^{\circ} \mathrm{C}$ ) were run in the same PCR buffer. The products were digested by HindIII enzyme and analyzed by $3 \%$ agarose gel electrophoresis. The 109 bp product was cleaved into two fragments, 24 and $85 \mathrm{bp}$, by the digestion.

2.8. Genotyping for the Secretor Genes. The Secretor genotype was determined for the C357T, A385T, and G428A polymorphic sites and the fusion gene. Both $S e$ and $S e^{357}$ alleles have full enzyme activity. The $s e^{428}, s e^{385}, s e^{357 / 385}$, and $s e^{f u s}$ alleles confer little or no enzymatic activity relative to the $\mathrm{Se}$ and $\mathrm{Se}^{357}$ alleles $[5,8]$. The $s e^{f u s}$ allele is due to fusion of the Secretor gene and a pseudogene.
(1) PCR-CTPP for the Detection of the A385T Mutation and the Fusion Gene. To detect the A385T mutation and the fusion gene, the genotyping was conducted by means of PCR-CTPP [14]. The primers were as follows [16]: Se5-F0, 5' -TTT CAC TGC CAC CAG CAC CTG-3'; Se385-F1, $5^{\prime}$-ATC AAA GGC ACT GGG ACC CAG-3'; Se385-R1, 5' -GGA CGT ACT CCC CCG GGA T-3'; Se385-F2, $5^{\prime}$-TGG AGG AGG AAT ACC GCC ACT-3 ${ }^{\prime}$; Se385-R2, $5^{\prime}$-GTC CCC TCG GCG AAC ATG G-3'. Genomic DNA (30-100 ng) was used for each $25 \mu \mathrm{L}$ reaction mixture containing $0.2 \mathrm{mM}$ dNTPs, $10 \mathrm{pmol}$ each of the five primers, $2.5 \mu \mathrm{L}$ glycerol, 0.6 units of Taq polymerase (Takara, Shiga, Japan), $2.5 \mu \mathrm{L}$ 10x PCR buffer, and $1.5 \mathrm{mM}$ $\mathrm{MgCl}_{2}$. PCR conditions were 3 minutes of initial denaturation at $94^{\circ} \mathrm{C}$, followed by 35 cycles of 30 seconds at $94^{\circ} \mathrm{C}, 30$ seconds at $61^{\circ} \mathrm{C}$, and 30 seconds at $72^{\circ} \mathrm{C}$, and final extension at $72^{\circ} \mathrm{C}$ for 5 minutes. Amplified DNA was visualized on a $2 \%$ agarose gel containing ethidium bromide. In the Secretor A385T and the fusion genotyping by the PCR-CTPP, the amplified bands with $284 \mathrm{bp}, 216 \mathrm{bp}$, and $353 \mathrm{bp}$ represented the A allele, T allele, and $s e^{f u s}$ allele, respectively. A common band of $460 \mathrm{bp}$ appeared for the A and T alleles.

(2) PCR-RFLP for the Detection of the C357T and G428A Mutations. The C357T and G428A mutations were determined by PCR-RFLP. For the detection of the C357T mutation, the first PCR amplification with the primers Se-F $\left(5^{\prime}\right.$ CTC GAA TTC GGG CCT CCA TCT CCC AGC TAA C$\left.3^{\prime}\right)$ and Se-R $\left(5^{\prime}\right.$-CTC AAG CTT GCT TCT CAT GCC CGG GCA CTC- $\left.3^{\prime}\right)$ was performed [6]. The Se-F and Se-R primers (10 pmol) were added to $5 \mu \mathrm{L}$ of genomic DNA in total volume of $50 \mu \mathrm{L}$ containing $0.2 \mathrm{mM}$ of each dNTP, 0.1 unit of Taq polymerase (Takara, Shiga, Japan), $5 \mu \mathrm{L}$ 10x PCR buffer, and $1 \mathrm{mM} \mathrm{MgCl}{ }_{2}$. Thirty cycles $\left(30\right.$ seconds at $94^{\circ} \mathrm{C}, 30$ seconds at $65^{\circ} \mathrm{C}$, and 30 seconds at $72^{\circ} \mathrm{C}$ ) were run. For the second PCR, one $\mu \mathrm{L}$ of the first PCR product was used as the template by the primer sets 357-F (5'-CAG GAT CCC CTG GCA GAA CTA CCA CAT TAA- $\left.3^{\prime}\right)$ and 357-R (5'-AGC AGG GGT AGC CGG TGA AGC GGA CGT ACT-3') [6]. PCR was performed in $25 \mu \mathrm{L}$ reaction mixture containing $10 \mathrm{pmol}$ each primer, 0.2 units of Taq polymerase (Takara, Shiga, Japan), $0.1 \mathrm{mM}$ dNTPs, $2.5 \mu \mathrm{L}$ 10x PCR buffer, and $4 \mathrm{mM} \mathrm{MgCl}_{2}$. The second PCR was carried out under the same conditions as in the first PCR. The 357-F primer created an AseI site in the second PCR product from the mutant allele having C357T, and the $98 \mathrm{bp}$ product was cleaved into two fragments, 28 and $70 \mathrm{bp}$, by the digestion.

For detection of the G428A nonsense mutation, the first PCR was performed under the same primers and conditions as in the first PCR for detection of the C357T mutation. The second PCR was performed by the primers, 428-F ( $5^{\prime}$-CGC TTC ACC GGC TAC CCC TGC TTC T- $\left.3^{\prime}\right)$ and 428-R ( $5^{\prime}$ AAC TTC TGG GCC TCC TCC CGC A-3') [6]. PCR was performed in $25 \mu \mathrm{L}$ reaction mixture containing 10 pmol each primer, 0.2 units of Taq polymerase (Takara, Shiga, Japan), $0.1 \mathrm{mM}$ dNTPs, $2.5 \mu \mathrm{L} \mathrm{10x}$ PCR buffer, and $4 \mathrm{mM} \mathrm{MgCl}_{2}$. Thirty cycles $\left(30\right.$ seconds at $94^{\circ} \mathrm{C}, 30$ seconds at $60^{\circ} \mathrm{C}$, and 30 seconds at $72^{\circ} \mathrm{C}$ ) were run. In case of the product having the G428A mutation, the $107 \mathrm{bp}$ product might be separated into two fragments, 23 and $84 \mathrm{bp}$, by $\mathrm{XbaI}$ digestion. 
TABLE 1: Lewis genotype and allele frequencies by erythrocyte Lewis phenotype* .

\begin{tabular}{|c|c|c|c|c|c|}
\hline & $\begin{array}{c}\mathrm{Le}(\mathrm{a}-\mathrm{b}-) \\
(n=26)\end{array}$ & $\begin{array}{c}\mathrm{Le}(\mathrm{a}+\mathrm{b}-) \\
(n=54)\end{array}$ & $\begin{array}{c}\mathrm{Le}(\mathrm{a}-\mathrm{b}+) \\
(n=128)\end{array}$ & $\begin{array}{c}\mathrm{Le}(\mathrm{a}+\mathrm{b}+) \\
(n=1)\end{array}$ & \\
\hline$L e / L e$ & $6^{* *}$ & 33 & 69 & 0 & 108 \\
\hline$L e / l e^{59 / 508}$ & $14^{* *}$ & 20 & 45 & 0 & 79 \\
\hline$L e / l e^{59 / 1067}$ & $2^{* *}$ & 1 & 9 & 1 & 13 \\
\hline$L e / L e^{59}$ & 0 & 0 & 4 & 0 & 4 \\
\hline$l e^{59 / 508} / l e^{59 / 508}$ & 4 & 0 & $1^{* *}$ & 0 & 5 \\
\hline Le allele & 28 & 87 & 196 & 1 & $312(74.6)$ \\
\hline$l e^{59 / 508}$ allele & 22 & 20 & 47 & 0 & 89 (21.3) \\
\hline$l e^{59 / 1067}$ allele & 2 & 1 & 9 & 1 & $13(3.1)$ \\
\hline$L e^{59}$ allele & 0 & 0 & 4 & 0 & $4(1.0)$ \\
\hline
\end{tabular}

${ }^{*}$ Values are number or number (percentage).

** Inconsistency between the erythrocyte Lewis phenotypes and the Lewis phenotypes by the inference from Lewis genotypes.

TABLE 2: Secretor genotype and allele frequencies by erythrocyte Lewis phenotype.

\begin{tabular}{|c|c|c|c|c|c|}
\hline & $\begin{array}{c}\mathrm{Le}(\mathrm{a}-\mathrm{b}-) \\
(n=26)\end{array}$ & $\begin{array}{c}\mathrm{Le}(\mathrm{a}+\mathrm{b}-) \\
(n=54)\end{array}$ & $\begin{array}{c}\mathrm{Le}(\mathrm{a}-\mathrm{b}+) \\
(n=128)\end{array}$ & $\begin{array}{c}\mathrm{Le}(\mathrm{a}+\mathrm{b}+) \\
(n=1)\end{array}$ & \\
\hline $\mathrm{Se} / \mathrm{Se}^{357}$ & 1 & 0 & 1 & 0 & 2 \\
\hline $\mathrm{Se} / \mathrm{se}^{385}$ & 1 & $1^{*}$ & 0 & 0 & 2 \\
\hline $\mathrm{Se} / \mathrm{se} e^{357 / 385}$ & 9 & $4^{*}$ & 56 & 0 & 69 \\
\hline $\mathrm{Se} / \mathrm{se} e^{f u s}$ & 0 & 0 & 1 & 0 & 1 \\
\hline$S e^{357} / \mathrm{Se}^{357}$ & 0 & $1^{*}$ & 1 & 0 & 2 \\
\hline$S e^{357} / s e^{357 / 385}$ & 4 & 2 & 34 & 0 & 40 \\
\hline$S e^{357} / s e^{f u s}$ & 2 & 0 & 33 & 0 & 35 \\
\hline$s e^{385} / s e^{357 / 385}$ & 7 & 18 & 0 & 1 & 26 \\
\hline$s e^{357 / 385} / s e^{357 / 385}$ & 2 & 25 & $1^{*}$ & 0 & 28 \\
\hline$s e^{357 / 385} / s e^{f u s}$ & 0 & 3 & $1^{*}$ & 0 & 4 \\
\hline Se allele & 11 & 5 & 58 & 0 & 74 \\
\hline$S e^{357}$ allele & 7 & 4 & 70 & 0 & 81 \\
\hline$s e^{385}$ allele & 8 & 19 & 0 & 1 & 28 \\
\hline$s e^{357 / 385}$ allele & 24 & 77 & 93 & 1 & 195 \\
\hline$s e^{f u s}$ allele & 2 & 3 & 35 & 0 & 40 \\
\hline
\end{tabular}

${ }^{*}$ Inconsistency between the erythrocyte Lewis phenotypes and the Lewis phenotypes by the inference from Secretor genotypes.

\section{Results}

Lewis phenotypes (from erythrocyte, saliva, and gastric mucosa), Secretor genotypes, and Lewis genotypes were determined in 209 patients. The number of individuals with erythrocyte phenotype Le(a-b-), Le $(a+b-), \operatorname{Le}(a-b+)$, and $\mathrm{Le}(\mathrm{a}+\mathrm{b}+)$ was $26(12.4 \%), 54(25.8 \%), 128(61.2 \%)$, and 1 $(0.5 \%)$, respectively, among the 209 individuals. The number of patients with saliva phenotype Le $(a-b-), \operatorname{Le}(a+b-)$, Le $(\mathrm{a}-\mathrm{b}+)$, and Le $(\mathrm{a}+\mathrm{b}+)$ was 5 (2.4\%), 57 (27.3\%), 147 (70.3\%), and $0(0.0 \%)$, respectively. Lewis antigen expression on gastric mucosa was as follows: Le(a-b-), 17 (8.1\%); Le(a+b-), 14 (6.7\%); Le(a-b+), 95 (45.5\%); Le(a+b+), 83 (39.7\%).

The frequency of occurrence of the $L e, l e^{59 / 508}, l e^{59 / 1067}$, and $L e^{59}$ alleles was $74.6 \%, 21.3 \%, 3.1 \%$, and $1.0 \%$, respectively, among 418 alleles examined in total (Table 1). The $l e^{59 / 508}$ allele accounted for $87.3 \%$ of the le alleles, whereas the $l e^{59 / 1067}$ allele was $12.7 \%$. The frequency of the $\mathrm{Se}, \mathrm{Se}^{357}, s e^{385}, s e^{357 / 385}$, and $s e^{f u s}$ alleles was $17.7 \%, 19.4 \%, 6.7 \%, 46.7 \%$, and $9.6 \%$, respectively, among 418 alleles examined in total (Table 2).

Tables 1 and 2 summarized whether Lewis phenotype on erythrocytes and known mutations of Lewis gene or Secretor gene corresponded. In Table 3, various Lewis phenotypes (saliva, erythrocytes, and gastric mucosa) were compared with the Lewis phenotype predicted from Lewis and Secretor genotypes. The saliva Lewis phenotype was completely consistent with the Lewis phenotype inferred from Lewis and Secretor genotypes, but the Lewis phenotype in gastric mucosa could not be predicted from Lewis and Secretor genotypes.

\section{Conclusion}

One out of purposes of the present study was to examine the correspondence between Lewis phenotype on RBCs and 
TABLE 3: Comparison between various Lewis phenotypes and the Lewis phenotype predicted from Lewis and Secretor genotypes.

\begin{tabular}{|c|c|c|c|c|c|c|c|c|c|c|}
\hline & \multicolumn{3}{|c|}{ le/le and -/- } & \multicolumn{2}{|c|}{ Le/- and se/se } & \multicolumn{4}{|c|}{$\mathrm{Le} /-$ and $\mathrm{Se} /-$} & \\
\hline & le/le & le/le & le/le & Le/Le & Le/le & $L e / L e$ & Le/Le & Le/le & Le/le & \\
\hline & $\mathrm{Se} / \mathrm{Se}$ & $\mathrm{Se} / \mathrm{se}$ & se/se & se/se & se/se & $\mathrm{Se} / \mathrm{Se}$ & $\mathrm{Se} / \mathrm{se}$ & $\mathrm{Se} / \mathrm{Se}$ & Se/se & \\
\hline & \multicolumn{3}{|c|}{$\operatorname{Le}(a-b-)$} & \multicolumn{2}{|c|}{$\operatorname{Le}(a+b-)$} & & \multicolumn{2}{|c|}{$\operatorname{Le}(a-b+)$} & & \\
\hline \multicolumn{11}{|c|}{ Lewis phenotype in saliva* } \\
\hline $\operatorname{Le}(a-b-)$ & 0 & 4 & 1 & 0 & 0 & 0 & 0 & 0 & 0 & 5 \\
\hline $\operatorname{Le}(a+b-)$ & 0 & 0 & 0 & 31 & 26 & 0 & 0 & 0 & 0 & 57 \\
\hline $\operatorname{Le}(\mathrm{a}-\mathrm{b}+)$ & 0 & 0 & 0 & 0 & 0 & 3 & 78 & 1 & 65 & 147 \\
\hline $\operatorname{Le}(a+b+)$ & 0 & 0 & 0 & 0 & 0 & 0 & 0 & 0 & 0 & 0 \\
\hline \multicolumn{11}{|c|}{ Lewis phenotype on erythrocytes } \\
\hline $\operatorname{Le}(\mathrm{a}-\mathrm{b}-)$ & 0 & 3 & 1 & 3 & 5 & 0 & 3 & 1 & 10 & 26 \\
\hline $\operatorname{Le}(a+b-)$ & 0 & 0 & 0 & 27 & 19 & 1 & 5 & 0 & 2 & 54 \\
\hline $\operatorname{Le}(a-b+)$ & 0 & 1 & 0 & 1 & 1 & 2 & 70 & 0 & 53 & 128 \\
\hline $\operatorname{Le}(a+b+)$ & 0 & 0 & 0 & 0 & 1 & 0 & 0 & 0 & 0 & 1 \\
\hline \multicolumn{11}{|c|}{ Lewis phenotype in gastric mucosa ${ }^{* *}$} \\
\hline $\operatorname{Le}(\mathrm{a}-\mathrm{b}-)$ & 0 & 1 & 1 & 0 & 1 & 0 & 3 & 1 & 10 & 17 \\
\hline $\operatorname{Le}(a+b-)$ & 0 & 0 & 0 & 6 & 4 & 0 & 3 & 0 & 1 & 14 \\
\hline $\operatorname{Le}(a-b+)$ & 0 & 3 & 0 & 1 & 1 & 1 & 44 & 0 & 45 & 95 \\
\hline $\operatorname{Le}(a+b+)$ & 0 & 0 & 0 & 24 & 20 & 2 & 28 & 0 & 9 & 83 \\
\hline
\end{tabular}

* The saliva Lewis phenotype through the hemagglutination inhibition test was consistent with the Lewis phenotype inferred from Lewis and Secretor genotypes.

${ }^{* *}$ The Lewis phenotype in gastric mucosa by immunohistochemistry was not predicted from Lewis and Secretor genotypes.

known mutations of Lewis gene. Moreover various Lewis phenotypes (saliva, erythrocytes, and gastric mucosa) were compared with the Lewis phenotype predicted from Lewis and/or Secretor genotypes.

Erythrocyte phenotyping through the conventional hemagglutination test has been regarded as a simple way of determining the Lewis antigens. However, in view of our study, erythrocyte phenotyping seems to be incapable of determining accurate Lewis phenotypes. The erythrocyte phenotype is influenced by many factors and may not necessarily reflect someone's Lewis and Secretor genotypes. The adsorption of glycolipid carrying Lewis activities from plasma onto erythrocytes is sometimes prevented. Some diseases are known to decrease the concentration of circulating Lewis-active glycolipids and cause the incompatible expression of Lewis antigens on erythrocytes. The expression of Lewis antigens has also demonstrated to be affected by the presence of tumors in cancer patients [4].

Lewis phenotyping using erythrocytes is only adequate for transfusion needs. Up to the present, many studies, which have been performed to establish if a disease associates with the Lewis blood group, were not correctly determined the Lewis phenotypes. Therefore, for accurate Lewis phenotyping, alternative methods must be used. In this study, the methods of genotyping and gastric immunohistochemical phenotyping resolved the above problems. However, molecular genotyping only provided an adjunct to phenotyping because the genotyping methods were unable to detect as yet undetermined mutations.

We have calculated Hardy-Weinberg equilibrium (HWE) for our data using Arlequin 3.5.1.3 [17]. The distribution of alleles in the population of our study was deviated from the Hardy-Weinberg equilibrium $(P<0.05)$. Not only our study but also several other studies about Secretor and Lewis genes shows deviation from $\operatorname{HWE}[18,19]$. The C357T single nucleotide polymorphism (SNP) is normally present in conjunction with other SNPs of Secretor gene. By contrast, the isolated form of the $\mathrm{Se}^{357}$ allele was present at a relatively high frequency, which indicates the possibility that other combinations of C357T may exist, involving mutations that were not investigated in this population. It is also attributed to the ethnic composition of the sample and the change in population structures. In addition, HWE generally tends to be due to a deficit of heterozygotes for SNP, since the allelic dropout may be the most prevalent genotyping error [20]. Interestingly, our result of HWE calculation revealed deviation due to a deficit of homozygotes. Another possibility of the HWE disequilibrium may be the use of different amplification methods for genotyping, including different DNA polymerase, among studies $[14,16]$, and it might lead to misjudging the FUT2 genotype.

When the Lewis phenotype predicted from Lewis and Secretor genotypes was compared with various Lewis phenotypes (saliva, erythrocytes, and gastric mucosa), the Lewis phenotype obtained from saliva was completely consistent with the Lewis phenotype predicted from Lewis and Secretor genotypes, but the Lewis phenotype in gastric mucosa was unpredictable. Saliva testing for the Lewis phenotype appears to be a more reliable method for determining the peripheral Lewis phenotype of an individual because the Lewis antigens are not intrinsic to the erythrocytes but adsorbed onto erythrocyte membranes from plasma. Moreover saliva Lewis phenotyping through the hemagglutination inhibition test seems to be able to be used as a simple substituting method 
for determining the Lewis phenotype by the inference from Lewis and Secretor genotypes. Because the Lewis expression in gastric mucosa is a different one from the Lewis phenotype by the inference from Lewis and Secretor genotypes, the gastric Lewis phenotype must be used for the study on the association between the Lewis phenotype and Helicobacter pylori.

\section{Conflict of Interests}

The authors declare that there is no conflict of interests regarding the publication of this paper.

\section{References}

[1] Y. Koda, M. Soejima, and H. Kimura, "The polymorphisms of fucosyltransferases," Legal Medicine, vol. 3, no. 1, pp. 2-14, 2001.

[2] R. Mollicone, S. E. H. Moore, N. Bovin et al., "Activity, splice variants, conserved peptide motifs, and phylogeny of two New $\alpha 1,3$-fucosyltransferase families (FUT10 and FUT11)," Journal of Biological Chemistry, vol. 284, no. 7, pp. 4723-4738, 2009.

[3] R. Mollicone, I. Reguigne, R. J. Kelly et al., "Molecular basis for Lewis $\alpha(1,3 / 1,4)$-fucosyltransferase gene deficiency (FUT3) found in Lewis-negative Indonesian pedigrees," Journal of Biological Chemistry, vol. 269, no. 33, pp. 20987-20994, 1994.

[4] S. Nishihara, H. Narimatsu, H. Iwasaki et al., "Molecular genetic analysis of the human Lewis histo-blood group system," Journal of Biological Chemistry, vol. 269, no. 46, pp. 29271-29278, 1994.

[5] Y. Koda, M. Soejima, Y. Liu, and H. Kimura, "Molecular basis for secretor type $\alpha(1,2)$-fucosyltransferase gene deficiency in a Japanese population: a fusion gene generated by unequal crossover responsible for the enzyme deficiency," American Journal of Human Genetics, vol. 59, no. 2, pp. 343-350, 1996.

[6] T. Kudo, H. Iwasaki, S. Nishihara et al., "Molecular genetic analysis of the human lewis histo-blood group system: II. Secretor gene inactivation by a novel single missense mutation A385T in Japanese nonsecretor individuals," Journal of Biological Chemistry, vol. 271, no. 16, pp. 9830-9837, 1996.

[7] Y. Liu, Y. Koda, M. Soejima, N. Uchida, and H. Kimura, "PCR analysis of Lewis-negative gene mutations and the distribution of Lewis alleles in a Japanese population," Journal of Forensic Sciences, vol. 41, no. 6, pp. 1018-1021, 1996.

[8] H. Narimatsu, H. Iwasaki, F. Nakayama et al., "Lewis and Secretor gene dosages affect CA19-9 and DU-PAN-2 serum levels in normal individuals and colorectal cancer patients," Cancer Research, vol. 58, no. 3, pp. 512-518, 1998.

[9] E. M. Matzhold, W. Helmberg, T. Wagner et al., "Identification of 14 new alleles at the fucosyltransferase 1, 2, and 3 loci in Styrian blood donors, Austria," Transfusion, vol. 49, no. 10, pp. 2097-2108, 2009.

[10] M. Soejima, R. Fujimoto, T. Agusa et al., "Genetic variation of FUT2 in a Vietnamese population: identification of two novel Se enzyme-inactivating mutations," Transfusion, vol. 52, no. 6 , pp. 1268-1275, 2012.

[11] T. Borén, P. Falk, K. A. Roth, G. Larson, and S. Normark, "Attachment of Helicobacter pylori to human gastric epithelium mediated by blood group antigens," Science, vol. 262, no. 5141, pp. 1892-1895, 1993.

[12] D. Ilver, A. Arnqvist, J. Ögren et al., "Helicobacter pylori adhesin binding fucosylated histo-blood group antigens revealed by retagging," Science, vol. 279, no. 5349, pp. 373-377, 1998.
[13] M. Gerhard, N. Lehn, N. Neumayer et al., "Clinical relevance of the Helicobacter pylori gene for blood-group antigen-binding adhesin," Proceedings of the National Academy of Sciences of the United States of America, vol. 96, no. 22, pp. 12778-12783, 1999.

[14] N. Hamajima, T. Saito, K. Matsuo, and K. Tajima, "Competitive amplification and unspecific amplification in polymerase chain reaction with confronting two-pair primers," Journal of Molecular Diagnostics, vol. 4, no. 2, pp. 103-107, 2002.

[15] A. Shibata, N. Hamajima, Y. Ikehara et al., "ABO blood type, Lewis and Secretor genotypes, and chronic atrophic gastritis: a cross-sectional study in Japan," Gastric Cancer, vol. 6, no. 1, pp. 8-16, 2003.

[16] N. Hamajima, A. Shibata, Y. Ikehara et al., "Lack of consistency in the associations of Helicobacter pylori seropositivity with Se and Le polymorphisms among Japanese," Gastric Cancer, vol. 5, no. 4, pp. 194-200, 2002.

[17] L. Excoffier, G. Laval, and S. Schneider, "Arlequin (version 3.0): an integrated software package for population genetics data analysis," Evolutionary Bioinformatics Online, vol. 1, pp. 47-50, 2005.

[18] Y. Koda, T. Ishida, H. Tachida et al., "DNA sequence variation of the human ABO-secretor locus (FUT2) in New Guinean populations: possible early human migration from Africa," Human Genetics, vol. 113, no. 6, pp. 534-541, 2003.

[19] T. C. Corvelo, S. de Loiola Rdo, D. C. Aguiar et al., "The Lewis histo-blood group system: molecular analysis of the $59 \mathrm{~T}>\mathrm{G}$, $508 \mathrm{G}>\mathrm{A}$, and $1067 \mathrm{~T}>\mathrm{A}$ polymorphisms in an Amazonian population," PLoS ONE, vol. 8, no. 7, Article ID e69908, 2013.

[20] S. Sen and M. Burmeister, "Hardy-Weinberg analysis of a large set of published association studies reveals genotyping error and a deficit of heterozygotes across multiple loci," Human genomics, vol. 3, no. 1, pp. 36-52, 2008. 

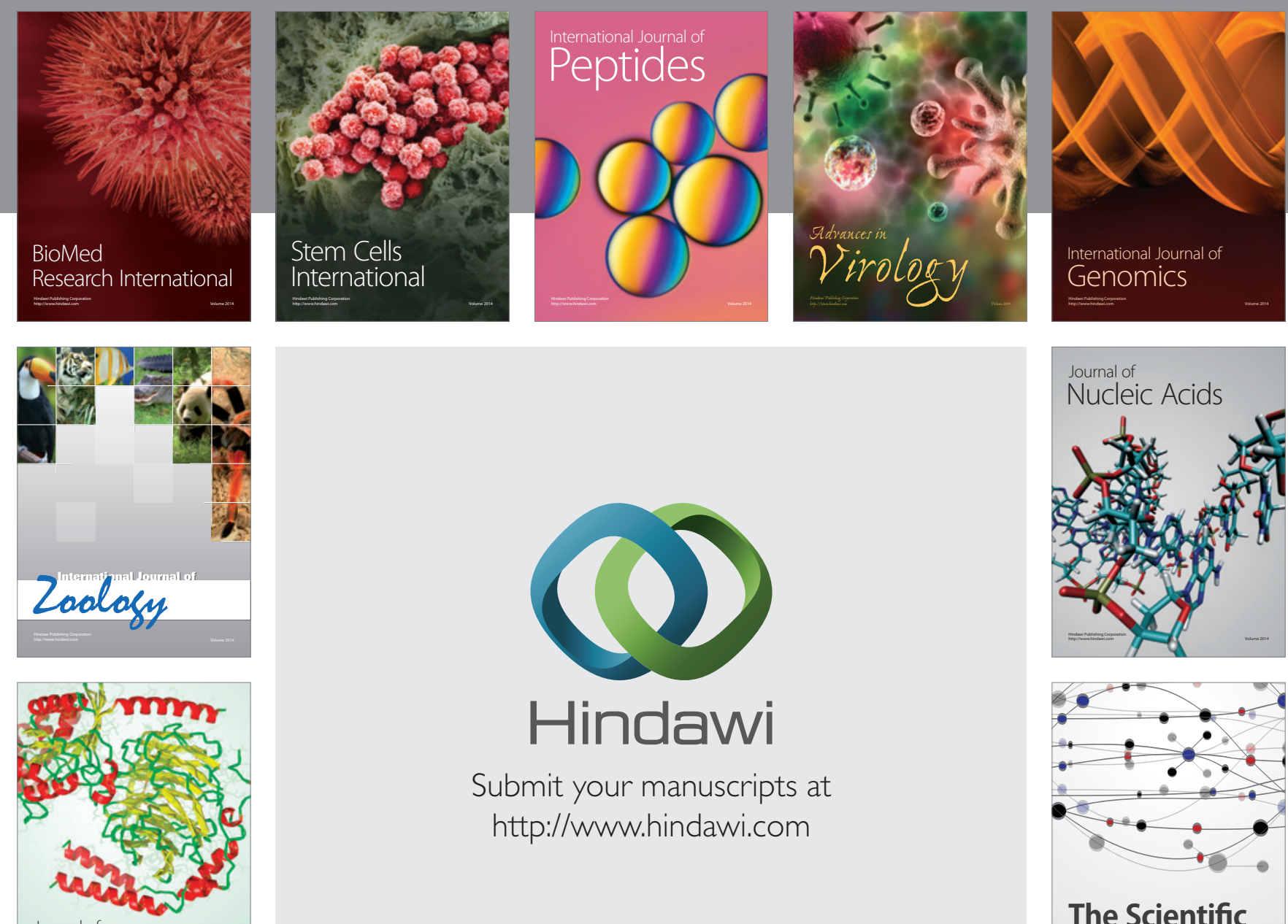

Submit your manuscripts at

http://www.hindawi.com

Journal of
Signal Transduction
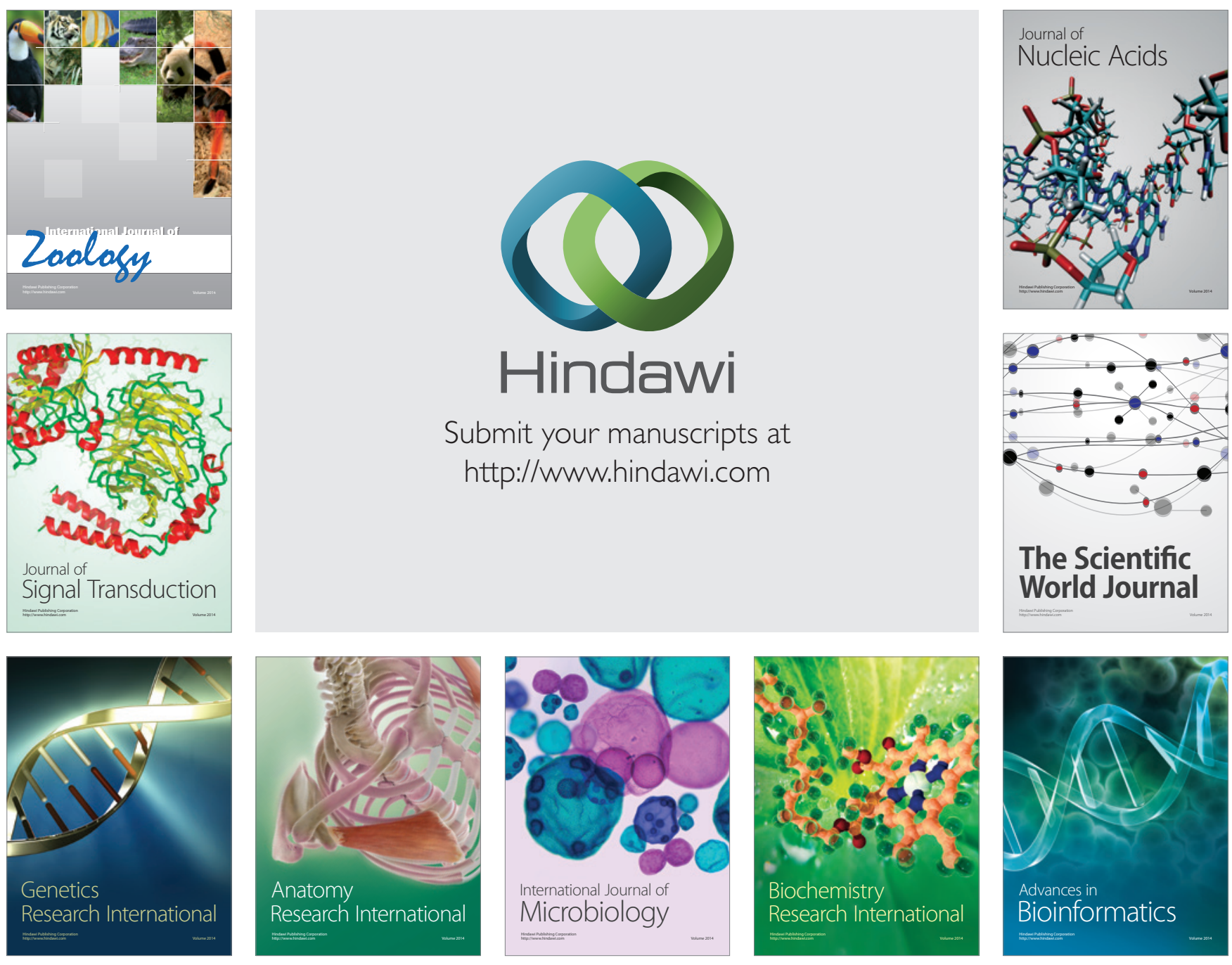

The Scientific World Journal
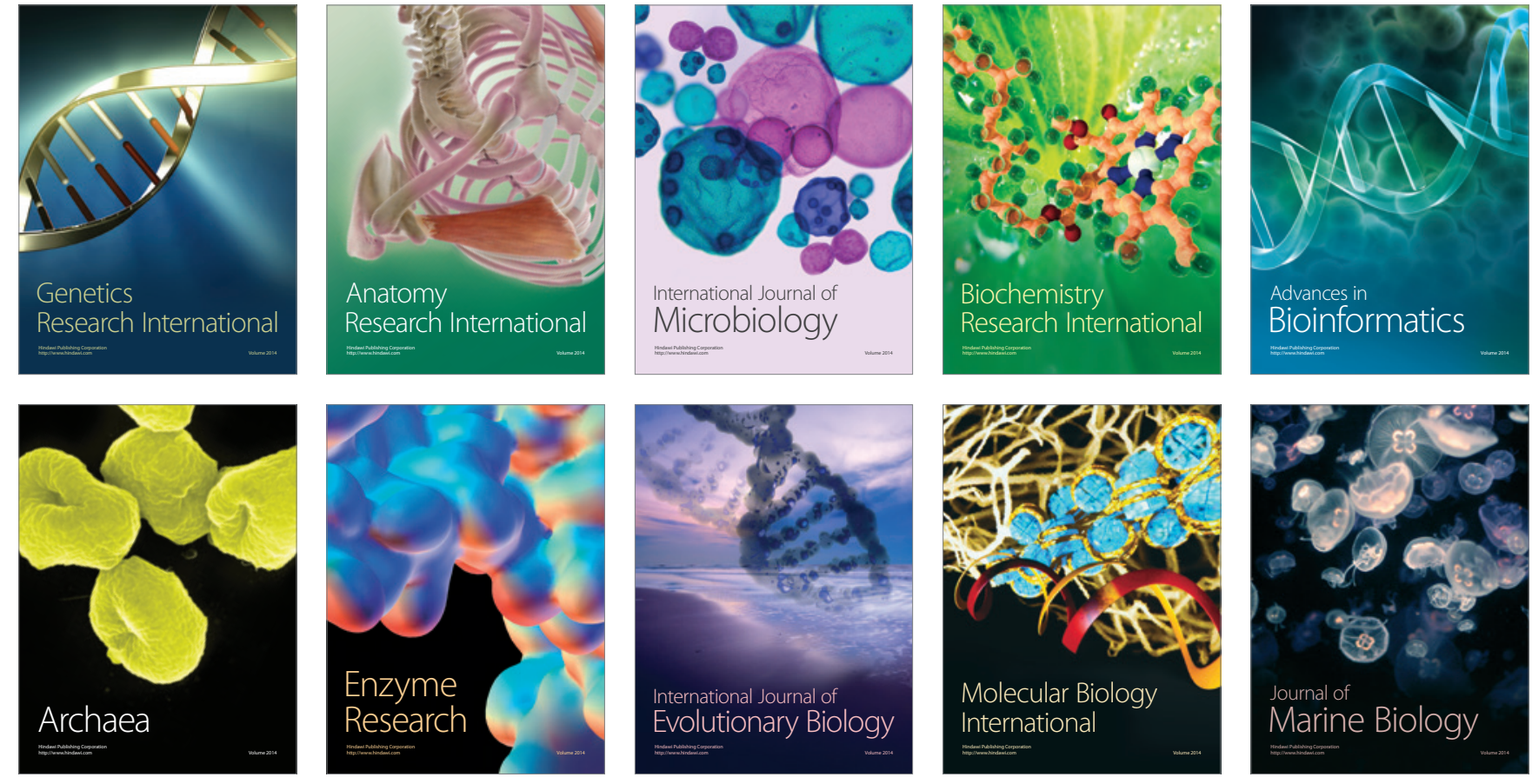